\title{
Pascual de Hontañón y la prostitución gaditana del último tercio del siglo XXX: saber médico frente a moralidad pública
}

\author{
FRANCISCO VAZQUEZ GARCIA \\ ANDRES MORENO MENGIBAR
}

\section{LOS DISPOSITIVOS DE CONTROL DE LA PROSTITUCION}

Este artículo forma parte de un conjunto más vasto de investigaciones, en proceso de realización, que tienen como horizonte general el análisis de la formación histórica de la identidad femenina en el curso de los últimos siglos. Concretamente, esta serie de trabajos toman como objeto de estudio la constitución de esta identidad en el dominio de la sexualidad, trazando la genealogía de ciertas figuras características: la mujer bistérica, la dama fatal, la prostituta. Este último caso es el que sirve ahora como marco de referencia: ¿cómo se ha conformado la figura de la mujer bonrada por oposición y demarcación respecto a la perdida, la mala mujer?

Cádiz capital y algunas localidades de su entorno, como San Fernando o El Puerto de Santa María, aparecen reconocidas, a mediados del siglo pasado, como centros importantes en el comercio de la prostitución. Su condición de puertos de mar o de relevantes plazas militares las convierte sin duda en urbes idóneas para este género de transacción (1). Teniendo en cuenta este problema, el Dr. Pascual de Hontañón, eminente catedrático de Higiene en la Facultad de Medicina de la

(1) Sobre la importancia de la prostitución en este género de ciudades, cfr. GUARDIA, J.: "La prostitution en Espagne", en PARENT-DUCHATELET, A. De la prostitution dans la Ville de Paris. Paris, 1857, troisiéme ed, 2 vols, tome 2, pp. 792-793. 
Universidad de Cádiz, publica en 1865 una propuesta para reforzar las medidas sanitarias, administrativas y legales, que tenían como blanco a la población de las rameras (2).

Antes de entrar en el análisis detallado del sugerente texto de Hontañón, es indispensable situar su proyecto en la racionalidad político-asistencial donde cobra adecuado sentido. ¿En qué dispositivo de poder y de saber se sitúa su proposición? ¿A qué manera de gestionar, de gobernar y conocer los sujetos responden sus exigencias? Para afrontar estas preguntas es necesario referirse, sólo sea sucintamente, al régimen tecnopolítico, al sistema de estrategias que tomaba como objeto el control de la prostitución en la España del período que nos interesa. Esto sólo es posible si se perfila comparativamente ese régimen en relación con los que lo precedieron.

A pesar de no ser numerosas las monografias locales sobre la historia de la prostitución en España, y mucho menos las de alcance nacional, sus resultados permiten periodizar los tipos de control y de saber sobre el comercio carnal en tres grandes formas:

1. El sistema de prostíbulos públicos o mancebias municipales. Este régimen, generalizado en Europa desde la Baja Edad Media, se mantiene en España, con diferencia, hasta la segunda mitad del siglo XVII. La prostitución aparece institucionalizada en establecimientos regulados por Ordenanzas con sanción real, aprobadas y aplicadas por los Ayuntamientos. Estos reglamentos se renovaron y rectificaron con cierta periodicidad en España, desde las Partidas de Alfonso X hasta las ordenanzas decretadas en tiempos de Felipe III. Las mancebías, de propiedad particular (nobleza e incluso órdenes religiosas, por concesión de la Corona o delegación señorial), son arrendadas y puestas bajo la dirección de un administrador (el padre o la abadesa de la mancebía), siendo su gestión supervisada por la autoridad municipal.

(2) HONTAÑON, Pascual de: "Institución de los Médicos Higienistas. Resultados que deben esperarse de ella y medidas suceptibles de mejorarla", en La Crónica Médica, vol. 35 (1865), pp. 50-53 y 68-71. En el momento en que se publica su proyecto, Pascual de Hontañón y Cabezas estaba a punto de obtener plaza como catedrático supernumerario en la Facultad de Medicina de la Universidad gaditana: "El 5 de julio de 1860 fue nombrado Profesor Clínico de la Facultad. En mayo de 1866 obtuvo por oposición la plaza de catedrático supernumerario, adscribiéndosele las asignaturas de Higiene Privada, Higiene Pública, terapéutica médica y arte de recetar y Medicina legal. En 1866 ingresa como académico de número de la Real Academia de Medicina y Cirugía de Cádiz" (OROZCO ACUAVIVA, A.: Bibliografía Médico-Cientîfica Gaditana. Cádiz, Obra cultural "Casino Gaditano", 1981). 
El local de la mancebía, situado generalmente extramuros, obedece a un principio de fijación de espacios (concentración obligatoria del ejercicio de la prostitución en una zona de la ciudad), definiendo cercados permeables (se trata de un área tapiada, con puertas y cierres, aunque durante el día las mancebas pueden entrar y salir libremente) e identificando a sus usuarias profesionales mediante una serie de marcas simbólicas (prescripciones sobre el tocado, la vestimenta y los adornos del cuerpo). El comercio de estas prostitutas aparece interrumpido periódicamente por la obligada abstinencia en las fiestas religiosas, la asistencia frecuente a la liturgia eucarística y a los sermones y pláticas regularmente estipulados. De este modo, un tiempo sacro se intercala en los ritmos profanos del oficio.

Las ocupantes de la mancebía están sometidas a todo un conjunto de regulaciones. Pueden ejercer libremente su profesión en el interior del establecimiento, pero deben entregar parte de sus ingresos, a título de alquiler, al administrador del local, que oficiará como recaudador municipal. Por otra parte, están sometidas a una inspección médica, cuya periodicidad suele ser variable (de ocho a quince días para la mancebía de Sevilla) y tienen por objeto sustraer a las infectadas por la sífilis y depositarlas en los hospitales. No obstante, las prácticas que principalmente rigen la vida de las mancebas siguen el primado de la expiación religiosa y la purificación ritual. De entrada, la ramera admitida en la mancebía debe poseer los rasgos de la extraña, excluida por su procedencia del orden de la ciudad (no podía ser natural del municipio) y del sistema de las alianzas (no podía estar casada ni ser sus padres de la localidad). Los ritos de expiación (oraciones colectivas, misas, pláticas en un convento de la villa, sermones en la mancebía) tienen el objetivo de reintegrar periódicamente la exterioridad de la ramera y propiciar su arrepentimiento definitivo. Esta preponderancia de los contenidos religiosos explica la proximidad de la mancebía al modelo del convento: términos utilizados para designar el establecimiento y sus administradores, austeridad de las boticas, similares a celdas, frugalidad en el régimen horario y alimenticio, sencillez en el porte de las profesionales (3).

(3) Sobre el régimen de las mancebías pueden consultarse los siguientes estudios. M.T. LOPEZ BELTRAN: La prostitución en el reino de Granada en época de los Rejes Católicos: el caso de Málaga (1487-1516). Málaga, 1985. Id. "Evolución de la prostitución en el reino de Granada a través de las ordenanzas de la mancebía de Ronda", en el colectivo Realidad bistórica e invención literaria en torno a la mujer. Málaga, 1987. F. VAZQUEZ GARCIA y A. MORENO MENGIBAR. "Documentos sobre el prostíbulo municipal de Sevilla, siglos XVI-XIX", en Er, Revista de Filosofia, núm. 7/8 (1989). A. MORENO MENGIBAR: "Sexualidad y sociedad en Sevilla en los siglos XVI y XVII", en El siglo que viene, núm. 7 (1990). 
Por último, el sistema de las mancebías públicas se sostenía en el pretendido cumplimiento de una serie de funciones que equilibraban el sistema social: proteger la honorabilidad de las familias, alejando de la vista de las doncellas la exhibición escandalosa de las mundarias, y especialmente, evitar los raptos, violaciones y sus subsiguientes filiaciones ilegítimas. Esto último se aseguraba canalizando hacia el prostíbulo público las desbordadas energías de una excedente y violenta juventud soltera: En segundo lugar, se buscaban benéfiicos efectos para la paz pública, al concentrar en ciertos lugares de la ciudad al mundo criminal que siempre ha merodeado en torno al comercio carnal: rufianeria y alcahuetería, hampa, bribones y pendencieros. Por último, instalando a todas las prostitutas en un local sometido a inspección médica y persiguiendo a las rameras nómadas y clandestinas, se pretendían limitar los efectos devastadores de la sífilis (4).

2. El régimen de encierro correccional voluntario (casas de misericordia como las de Recogidas o Arrepentidas) u obligado (las casas de corrección, llamadas galeras). El funcionamiento del primer tipo de estos centros está atestiguado al menos desde el siglo XVI en España (en Sevilla, v.g., desde finales del siglo XVI); sin embargo, su reorganización y adecuada financiación sólo se produce a partir del decreto de Felipe IV aboliendo las mancebías en 1623 (así, por ejemplo, la fundación en Cádiz en 1678 del Asilo de San Pablo). Las galeras se ponen en marcha cuarenta años más tarde cuando, en 1661, Felipe IV decreta su instauración, destinándose a ellas las rameras detenidas por la justicia. Ambas fórmulas tienen sus momentos fuertes en los siglos XVII y XVIII, aunque las casas de Arrepentidas, integradas en la política asistencial de la Iglesia, se mantendrán casi hasta nuestros dias (en Sevilla hay aún una fundación de este tipo en 1859). La institución eclesiástica regenta en efecto este tipo de centros de corrección (gestionados por órdenes religiosas más o menos especializadas, como las monjas de Santa María Magdalena de la Penitencia, en el siglo XVII, o las Adoratrices, en el siglo XIX). Las galeras, prisiones de reclusión para mujeres, dependen directamente de la autoridad de la monarquía o de la administración municipal (así, en 1704 el Consejo de Castilla ordena la reclusión en casa de galera de todas las mujeres perdidas) (5). Eventualmente, este procedimiento de encierro se combinaba con el destierro.

(4) F. VAZQUEZ GARCIA y A. MORENO MENGIBAR: art. cit; pp. 328-333.

(5) Sobre esta orden, cfr. el art. "Prostitución", en TAPIA, Eugenio de: Tratado del Juicio Criminal. Valencia, 1829, p. 148. 
El sistema de internamiento obedece a un principio de exclusión mediante el aislamiento y el encierro disciplinario. Bien en mazmorras, bien en pabellones, las prostitutas o jóvenes descarriadas y denunciadas por sus familias, recluidas por propia voluntad o mediante el empleo de la fuerza, son sometidas a una moralización permanente a través del trabajo, la penitencia, la oración, la meditación, la cura de almas, la dirección espiritual y el castigo. El ritmo temporal de estas instituciones combina los momentos sacros de expiación y conversión religiosa con los periodos de trabajo disciplinario y moralizador. Desde esta perspectiva, las casas de misericordia, en las que se ingresa por reclusión voluntaria, ponen en marcha una intervención mucho más constante y calculada sobre las internas que en las casas de galera, convertidas con frecuencia en meros depósitos, almacenes de perdidas donde se separa y aisla un mal moral.

Si la mancebía pública integraba a la prostituta en el orden social marcando su diferencia y regulando su oficio, el sistema de encierro correccional pretende reconciliarla eliminando su diferencia (al sustraerla de toda visibilidad) y suprimiendo su profesión (corrigiendo, transformando su naturaleza salvaje y pecadora). A la ganancia política y social que pretendía obtener el régimen de las mancebías (manteniendo en equilibrio el orden de las alianzas, el orden público, preservando de los contagios), el régimen del encierro quiere añadir una ganacia moral (purificación de la carne fortaleciendo el afecto entre los esposos, depuración de los excesos libertinos de la juventud fomentando la obediencia, sacralización del trabajo). El dispositivo de las mancebías fracasó por el empuje de la Contrarreforma y su insistencia en los males de la carne; por la privatización paulatina del espacio y la moral familiar; por la división y rivalidad entre las instancias administrativas, la corrupción generalizada de gestores y ejecutores, la ineficacia del sistema policial. El sistema del encierro forzoso nunca llegó a funcionar efectivamente, limitándose a operaciones de reclusión masivas, pero intermitentes, eventuales, espaciadas, y la corrección disciplinaria, cuando raramente fue practicada, no conseguía en general la renuncia a volver al oficio. La prohibición de los lupanares en el derecho era de hecho la puesta en juego de una tolerancia y una negligencia sin trabas. Por otra parte hay que destacar, desde finales del siglo XVII, una creciente desconfianza entre las élites ilustradas hacia el sistema de encierro asilar propiciado por las monarquías absolutas, tanto por su arbitrariedad despótica como por lo improductivo de los bienes invertidos en tales instituciones. Los partidarios, desde comienzos del siglo 
XIX, de un modelo liberal de Estado, próximo al sistema inglés, se opondrán por ello a la intervención administrativa en la prohibición o regulación del comercio carnal. Paralelamente, las leyes liberales (Cortes de Cádiz, Ley de Beneficiencia de 1822, etc.) tenderán a incrementar el poder conferido a ayuntamientos y juntas provinciales en las instituciones de asistencia, frente al predominio casi exclusivo de los eclesiásticos.

3. El sitema de casas toleradas o burdeles registrados. Proyectada con frecuencia desde la propuesta de Cabarrús en 1792, la regulación sin supresión de los prostíbulos y su sumisión al imperio de la vigilancia médica, sólo comenzará a aplicarse en los municipios españoles a la altura de 1855. Merece la pena detenerse en las notas distintivas de este sistema, en el que se insertan las exigencias de la medicina gaditana, a través de Pascual de Hontañón.

Como recogen varios testimonios (6), en 1792 Cabarrús remitió a Godoy un proyecto en el que recomienda la reglamentación de las casas públicas como único remedio eficaz para frenar y finalmente suprimir los males, especialmente contra la salud, originados por el crecimiento ilimitado de la prostitución. En esta regulación, donde se aconsejan también eventuales medidas de deportación, Cabarrús menciona la necesaria intervención de la higiene y la policía médicas. Bajo el reinado de Fernando VII, los autores de un proyecto de ley orgánica sobre la salud pública propusieron un premio para la mejor memoria sobre los medios de controlar los efectos devastadores de la prostitución. En 1822 , el proyecto fue aprobado por las Cortes, pero se rechazó la autorización reglamentada de los burdeles. Se abre entonces en España un amplio debate entre los partidarios de la prohibición y los que sostienen la implantación de una tolerancia reglamentada. La Iglesia, numerosos políticos liberales e higienistas tan prestigiosos como Monlan, se oponen a la autorización controlada de los burdeles, pero, paulatinamente; se acaba imponiendo la posición de la mayoría de los sifilógrafos y médicos higienistas, cuerpo cada vez más influyente desde su creación en el primer tercio del siglo XIX, que defienden el modelo de prostitución tolerada pero registrada, reglamentada y sometida a vigilancia permanente.

El sistema de casas toleradas toma como referencia el paradigma francés (posteriormente perfeccionado en Bélgica), promocionado

(6) Cfr. GUARDIA, J.M.: op. cit, pp. 790-792 y MONLAU, P.F. Elementos de Higiene Pública, 2 vols. Madrid, 1871, $3^{2}$ ed, t. 2, pp. 632-633. 
desde la Restauración y puesto en marcha por la Monarquía de Julio. El mentor por excelencia del dispositivo fue Alexandre Parent-Duchatelet, cuyo imponente y enciclopédico estudio sobre la prostitución parisina apareció póstumamente en 1836 (7). Este médico higienista, que ha sido considerado como el padre de la sociología empírica, puso en marcha una fundamental investigación sobre las prostitutas de París, asentada sobre numerosos cuestionarios realizados sobre el terreno, aplicando las técnicas estadísticas de la época para examinar el número, edad y procedencia profesional y geográfica de las prostitutas, sus lazos de parentesco, las causas de ingreso en el oficio, su grado de alfabetización, etc. Junto a estos análisis cuantitativos realizó una verdadera tarea de etnólgo, describiendo minuciosamente los hábitos de vida en los burdeles, el carácter de las rameras, su detallada taxomanía.

El modelo de Parent-Duchatelet comenzó a ponerse en marcha en España a mediados de los años cincuenta del siglo pasado, por iniciativa y bajo gestión directa de los gobiernos civiles, que nombran las comisiones de médicos higienistas, llevan la vigilancia sanitaria de los prostíbulos y delegan en los ayuntamientos las medidas administrativas para el registro de las prostitutas, bien en sus domicilios, bien en las casas de lenocinio.

¿En qué consiste el sistema de las casas toleradas, que data en Cádiz capital, según Pascual de Hontañón, del año 1863?

A diferencia de lo que sucedía en las mancebías públicas, cuya ubicación urbana era oficialmente conocida y visiblemente destacada, la casa de tolerancia es un establecimiento de dirección privada, regentado por una matrona (profesional veterana, generalmente retirada), un local de discreta apariencia externa (en Francia se denominaban maisons closes). Su espacio interior, a diferencia de lo que ocurría en la mancebía, no ofrece un espectáculo austero y casi monacal; es un escenario de adorno e ilusión, escindido con frecuencia en un ámbito o sala de recepción y un conjunto de habitaciones privadas. La identi-

(7) Este libro tuvo cuatro ediciones: en $1836,1837,1857$ y 1900 . La más completa es la de 1857, que incluye un voluminoso dossier, realizado por diversos autores, sobre el estado de la prostitución en diversas partes del mundo. El historiador que ha investigado más a fondo la obra de Parent-Duchatelet y en general el fenómeno de la prostitución parisina en el siglo XIX es sin duda el profesor Alain Corbin, autor de Les Filles de Noce, Paris, Aubier Montaigen, 1978, y editor de una edición 'abregée' del libro de Paren-Duchatelet (La Prostitution a Paris au XIXe Siecle. Paris, seuil, 1981). 
dad de la prostituta no está, en este caso, fijada por unas marcàs simbólicas obligatorias y uniformes (la vestimenta y el tocado de las antiguas mancebas); obedece al arbitrio y capacidad adquisitiva de la profesional, y suele reconocerse por la profusión de afeites, lo exótico de los nombres, lo llamativo de los vestidos, la provocación de las posturas. Por otra parte, cada prostituta legalizada aparece registrada en una matrícula oficial, donde se especifica su procedencia, oficio original, edad y, eventualmente, otros datos de interés. Del mismo modo que en las mancebías, algunos autores recomiendan que los burdeles se emplacen en la periferia de las ciudades.

Las acciones que se ciernen sobre la prostituta obedecen a un imperativo médico; el higienista pone en juego una estructura supervisora donde el control del burdel se inserta en una estrategia más amplia de planificación social (vigilancia de las poluciones del aire en los locales públicos, profilaxis médica de las viviendas, control de aguas y cloacas, saneamiento de mercados y cementerios, etc.). La prostitución no es sólo una amenaza moral; aparece revestida de los signos de una enfermedad social, equiparada al detritus y a los excrementos generados en las grandes urbes. La prostituta, por su parte, ofrece la imagen de la niña desvalida, una menor que exige tutela, caída en esa condición por las urgencias de la miseria o los efectos de la seducción (8).

La medicalización del prostíbulo es a la vez una vigilancia y control constantes, un ejercicio del poder y una acumulación de saber, desplegando técnicas de observación y clasificación rigurosas, tablas estadísticas a partir de índices variados, registro individualizado y seguimiento por casos, búsqueda de etiologías psíquicas y sociales. Por otra parte, los burdeles configuran un escenario abierto a la mirada médica, un laboratorio donde el higienista puede estudiar las patologías asociadas a la prostitución: sífilis, gonorreas y blenorragias, pero también metrorragias y excesos en los flujos mucosos uterinos, abscesos en los grandes labios, fístulas rectovaginales, perturbaciones de la visión y la audición, estados frenopáticos, convulsiones histéricas, alie-

(8) GINE Y PARTAGAS, J.: Curso elemental de Higiene Privada y Püblica, 2 vols. Barcelona, 1871, tomo 2, lecc. 55. Insiste en este concepto de la prostitución como enfermedad (pp. 316-317) y en el papel desempeñado por la seducción y la miseria para provocarla (pp. 318-321). Esta posición se reproduce en casi todos los higienistas preocupados en la época por eśte problema. 
naciones mentales, lesbianismo y criminalidad (9). La captación higienista del prostíbulo edifica toda una máquina de prevención médica y social. En este vigilancia, el higienista, el policía sanitario y la matrona establecen una jerarquía y un sistema de relevos.

Las funciones de esta sistema son, por tanto, eminentemente sanitarias y tienen como objetivo inmediato la prevención de la sífilis. Sin embargo, sus perspectivas son más elevadas, destinadas a la moralización general de la sociedad. Siendo imposible según los higienistas erradicar la prostitución por medidas prohibitivas directas, se puede al menos, conociendo sus causas, prevenir su origen, fomentando la instrucción de las clases populares, del sexo femenino, instigando a la moralización por el trabajo, combatiendo el lujo y el pauperismo.

La inevitabilidad del prostíbulo y la ineficacia de su prohibición se cifran en el fracaso de las medidas que pretendían suprimirlo. Se llegan incluso a señalar las bondades de la prostitución para fortalecer los valores de la familia burguesa: contribuye a canalizar los excesos de la sensualidad en un placer fugaz y sin compromisos; aminoran los peligros de la seducción, la disipación del orden doméstico y laboral, la amenaza de los partos extramatrimoniales (10). El burdel no es un elemento que haya que eliminar, sino más bien normalizar, registrando e inspeccionando a las prostitutas legalizadas, y persiguiendo y castigando a la prostitución clandestina. En este cudro de poder y de saber se localiza la propuesta de Hontañón.

(9) En esta "voluntad de saber," las técnicas utilizadas en el libro de Paren-Duchatelet son siempre citadas como modelo de investigación. Cfr. v.g. GINE Y PARTAGAS: op. cit, Pp. 318-321; MONLAU, P.F: Remedios del pauperismo, Valencia, 1846, pp. 22-23 (si bien Monlau se oponía a la prostitución reglamentada). En España puede citarse como modélico el trabajo de HAUS$\mathrm{SER}, \mathrm{Ph}$, Estudios médico-sociales de Sevilla, t. 2. Madrid, 1884, cap. III.

(10) GINE Y PARTAGAS, J.: op. cit, pp. 342-245. Insiste en las ventajas de la tolerancia reglamentada sobre el prohibicionismo, evitando los engaños de la prostitución clandestina, verdadera catástrofe para las familias. Este autor, siguiendo las líneas del Dr. Juan Magaz (Universidad de Barcelona), se opone así a las tesis prohibicionistas de Monlau. En Alemania (Dr. Rubner) o en Francia (Dr. Fleury) se encuentran argumentos a favor de la "utilidad social" de los prostíbulos, siempre que estén reglamentados y sometidos a inspección. Cfr. RUBNER, M.: Tratado de Higiene, tomo 2. Barcelona, s.a. (finales del siglo XIX), pp. 15-17. 


\section{LAS PROPUESTAS MEDICO-SOGIALES DEL DR. HONTAÑON}

Para Hontañón resulta fuera de duda la necesidad de establecer un cuerpo municipal de médicos higienistas, aunque su propuesta va más allá del ámbito municipal. El Gobierno debería intervenir en tema tan imperioso y otorgar una legislación única y homogénea para toda la nación, que acabase con las arbitrariedades y las irregularidades que en el tratamiento de la prostitución se observaban. Así, por ejemplo, mientras que Madrid contaba con 12 higienistas, Cádiz tenía 14 y San Fernando 2; era imposible hallar una proporción justa entre población, número de prostitutas y efectivos médicos mientras cada ayuntamiento pudiese reglamentar por su cuenta ese terreno. La petición de Hontañón, sin embargo, no tendría inmediata solución, pues no sería hasta la Real Orden de 1 de marzo de 1908 cuando se estableciese una normativa general y común que equiparara las políticas higienistas municipales; hasta entonces, cada ayuntamiento tuvo las manos libres para imponer una reglamentación permisiva o restrictiva, o una mayor o menor atención sanitaria: en Cádiz se reconocía a las prostitutas cada tres o cuatro días, pero en San Fernando sólo una vez a la semana. Para Hontañón, esta disparidad no lleva más que a la ineficacia en la lucha antivenérea; deben dejarse de lado los escrúpulos morales, y promulgar una legislación nacional y centralizar la formación de los médicos higienistas. Era ésta una de las exigencias básicas de cuantos habían tratado el tema del control médico de la prostitución, desde Parent-Duchatelet, en Francia, hasta Guardia, Giné y Partagás y Hauser, en España.

Lo anterior no se entendería, sin embargo, sin considerar, como hace el propio Hontañón, la necesidad de reglamentar la prostitución. Frente al abolicionismo que, desde Gran Bretaña, se extendería por Europa, el discurso médico propugna, ante la inevitabilidad del comercio carnal, su reglamentación. Para Hontañón, lejos de ser una inmoralidad, el control supone un progreso hacia una mejor condición de vida. Es interesante considerar cómo en este tema se da un enfrentamiento entre

(9) En esta "voluntad de saber" las técnicas utilizadas en el libro de Paren-Duchatelet son siempre citadas como modelo de investigación. Cfr. v.g. GINE Y PARTAGAS: op. cit, pp. 318-321; MONLAU, P.F: Remedios del pauperismo, Valencia, 1846, pp. 22-23 (si bien Monlau se oponía a la prostitución reglamentada). En España puede citarse como modélico el trabajo de HAUSSER, Ph, Estudios médico-sociales de Sevilla, t. 2. Madrid, 1884, cap. III. 
unas posiciones religiosas integristas, enemigas de que los poderes regùlen en modo alguno la prostitución, y unos postulados liberal-cientifistas en alza que ven en la legislación médica un paso hacia el bienestar de la Humanidad. Cuando los ediles de El Puerto de Santa María acordaron en 1875 restablecer el reglamento de la prostitución de 1864, se justificaron aduciendo el ejemplo de

Algunos países de los que marchan a la cabeza de la civilización y muchas capitales de provincias en nuestra patria (que) apartándose de pueriles y vanos escripulos, ban mirado frente a frente a la temerosa esfinge que exbibe por donde quiera su repugnante faz devorando la juventud y agostando con sus mortíferos efluvios los gérmenes de las generaciones futuras (11).

El propio Hontañón cita ejemplos de otros países y de otros tiempos para defender la extrema necesidad de vigilar y regular el ejercicio de la prostitución.

La reglamentación comienza por la clasificación de las propias prostitutas: las que viven y trabajan en los burdeles bajo la dirección de una matrona; las que sólo van a los burdeles a trabajar y viven por su cuenta, y las que trabajan por cuenta propia por las calles. Todas, y especialmente las últimas, deben estar registradas en las oficinas municipales de Higiene, y las que se nieguen a ello habrán de ser perseguidas. Las más peligrosas son, evidentemente, las que ejercen su oficio de forma ambulante, las que más escapan a la fijación de espacios. En una intervención en el Congreso Regional de Ciencias Médicas celebrado en Cádiz en agosto de 1879, Hontañón consideraría:

No es la sífilis escandalosa transmitida al joven a través de las inmundas rejas de una cortesana la más terrible; lo es mucho más la desarrollada por la prostitución clandestina, la que se oculta en los perfumados pliegues del vestido de una dama del gran mundo, la que ataca sorda y traidoramente, la que conculca la paz de las familias, y turba la dicha de los matrimonios. Contra ésta es contra la que debe desplegarse la mayor vigilancia... (12)

(11) Citado por F. PAREJA ORTIZ: "Mentalidad, Religiosidad y Moralidad Pública: la prostitución en el Puerto de Santa María en el último tercio del siglo XIX" en Actas del VII Congreso de Profesores-Investigadores. Motril, 1988, p. 497.

(12) Actas de las sesiones del. Congreso Regional de Ciencias Médicas celebrado en Cádiz del 10 al 14 de agosto de 1897. Cádiz, 1880, p. 77. 
A este respecto se destaca la coincidencia con otras propuestas, como la de Parent-Duchatelet y, sobre todo, con el reglamento de El Puerto de Santa María de 1864. Por la proximidad espacial y temporal habría que pensar si Hontañón parte del modelo portuense para su propuesta en Cádiz, o si, más probablemente, fue el inspirador, dada su posición en la vida de la bahía, del citado reglamento del Puerto.

Las prostitutas habrán de tener una cartilla sanitaria en la que se anoten las revisiones a las que se vayan sometiendo dos veces por semana, ya que, por término medio, el chancro sifilítico tarda unos cuatro días en aparecer. Al respecto, Hontañón exige un seguimiento mucho más intenso de lo que hasta el momento se venía haciendo, pues de unas 500 prostitutas que debía haber en Cádiz sólo pasaban revisión 300, y el peligro de infección, así, era patente. Dicho seguimiento debería ser llevado, para una mayor eficacia, conjuntamente por los higienistas y las fuerzas del orden, proponiendo la creación de una policía sanitaria que se hiciese cargo de ese campo de la vida pública. A pesar de su lógica interna, la propuesta era de difícil realización, pues supone un conflicto entre esferas de poder municipal difícilmente resoluble. Hauser nos informa en 1884 de la dificultad con la que se encuentran los higienistas para recabar la ayuda de la policía, pues ésta ve a los médicos como a unos competidores en la labor de vigilancia: pierden parte de su campo de poder e, incluso, se producen choques entre las estrategias de control de cada parte. Si al médico le interesa el perfil profiláctico del burdel, el policía busca en ellos a los soplones y a los rufianes; la permisividad policial respecto al prostíbulo se hace así inaceptable para el médico, y las exigencias de rigor de éste son igualmente inaceptables para el policía (13). De hecho, este conflicto de estrategias y de intereses debió de repercutir en la falta de efectividad del control antivenéreo en Cádiz, a lo cual contribuiría, sin duda, la falta de decisión de las autoridades locales para atajar de raíz el descontrol y el riesgo infeccioso. En el Congreso de 1879, el doctor gaditano Amado García Boulier expresó su crítica a la ineficacia del sistema seguido en Cádiz para controlar la higiene de la prostitución. En su opinión, el Gobierno ha de tomar medidas severas, ante la imposibilidad de extinguir la prostitución, para evitar los contagios. El sistema de visitas en días determinados seguido en Cádiz se muestra ineficaz por el alto grado de ocultación e incumplimiento que favorece. Un seguimiento eficaz había de pasar por la asignación del

(13) HAYSER, Ph.: op. cit, tomo II, pp. 199-200. 
tema en exclusiva a la clase médica: por un lado, formar auténticos espècialistas en Higiene y Sifilografía y asignarles unos salarios apropiados como para que se dedicasen exclusivamente a la lucha antivenérea; por otro, la redacción de reglamentos coherentes, redacción que habría de ser asignada a los médicos especialistas, y no a las autoridades gubernativas (14). Como se ve, la exigencia de una esfera exclusiva de poder para el saber médico, la búsqueda de un espacio propio de supervisión, se hace cada vez más intensa conforme nos adentramos en la España de la Restauración. En esta escalada, la prostitución y el peligro de las enfermedades venéreas jugarán un papel fundamental como argumento que justifique la inserción de las divisiones higiénicas en los ayuntamientos y la creación de los cuerpos de médicos municipales, culminando con el Real Decreto de 14 de junio de 1891 que creaba el Servicio Benéfico-Sanitario de los pueblos. Para la entonces influyente corriente médica degeneracionista, la sífilis era uno de los agentes patógenos más virulentos y con un mayor poder degenerativo; el organismo afectado sufria una serie de trastornos que retrotraían la evolución física y mental y que, además, eran hereditarios. En consecuencia, una prostitución clandestina o sin regulación médica suponía un enorme peligro para la supervivencia de la raza y de la vitalidad nacional. Nacionalismo y saber médico se alían en este terreno para exigir un control médico exclusivo del amor venal (15).

Cada burdel y cada prostituta habrían de pagar un pequeño canon por las revisiones médicas de que disfrutan, de forma que con dicha exacción se financie buena parte del servicio médico. Tal canon no habría de ser ni demasiado bajo como para que apenas si se cubrieran los gastos mínimos, ni demasiado elevado como para favorecer la clandestinidad.

Pero Hontañón va más allá en los objetivos últimos de su propuesta. A largo plazo, la única profilaxis efectiva contra las infecciones venéreas es

(14) Actas de las sesiones... op. cit, p. 70.

(15) La Francia derrotada de 1871 buscará en las enfermedades venéreas y en la prostitución incontrolada una de las principales causas de pérdida de la vitalidad nacional y de la escandalosa derrota frente a los ejércitos prusianos. En España, Hauser (Geografĩa médica de la Peníncula Ibérica, 2 vols, Madrid, 1913) se referirá a la sífilis como al mal que consume la raza. Sobre la corriente degeneracionista, cfr. HUERTAS GARCIA-ALEJO, Rafael: Locura y degeneración, Madrid, 1987; y PESET, José Luis: Ciencia y marginación. Barcelona 1983. 
la profilaxis social. Acabar con la pobreza, con el pauperismo que induce a las mujeres a prostituirse, es la única estrategia eficaz de lucha por la sanidad corporal y moral de la nación. Al mismo tiempo, una educación adecuada acabaría con los comportamientos delictivos y alejaría a los hombres de los burdeles; eliminada la demanda y las circunstancias económicas del mercado carnal, la prostitución se extinguiría por propia lógica económica.

El texto del catedrático gaditano termina con una llamada al sentimiento patriótico para crear una escuela nacional de higienistas que acabe con la dependencia de las obras extranjeras y que restablezca el prestigio pasado y perdido de los médicos españoles del siglo XVI. La creación de una sifilografía española sería el objetivo hacia el que debería tender la iniciativa del Gobierno que, de este modo, prestaría a los ciudadanos el mejor de los servicios.

No quisiéramos terminar sin destacar la importancia que el escrito de Hontañón presenta en el contexto de la lucha por la reglamentación de la prostitución en España. Tengamos en cuenta que el primer reglamento sanitario es el de 1858 para Madrid, reformado en 1865 (16). Hasta ese último año y hasta los años setenta no encontramos más reglamentaciones que la ya citada de El Puerto de Santa María y la propuesta de Pascual de Hontañón, ambas muy cercanas en su concepción y casi diríamos que obras de la misma mano. Los reglamentos de Sevilla, Barcelona, Vigo, San Sebastián, Gerona o Alcoy, coinciden plenamente con las ideas de Hontañón, y la Real Orden a la que hicimos referencia vendría a darle la razón cuarenta y tres años más tarde.

(10) CAPEL MARTINEZ, Rosa M".: "La prostitución en España: notas para un estudio socio-histórico" ${ }^{n}$ en el colectivo Mujer y Sociedad en España (1700-1975). Madrid, 1986, p. 284. 